\title{
Proximate Context of HIV-Related Stigma and Women's Use of Skilled Childbirth Services in Uganda
}

\author{
Courtney K NG ${ }^{1,}{ }^{*}$ Alexander C TSAI ${ }^{2}$ \\ ${ }^{1}$ Department of Global Health and Population, Harvard T.H. Chan School of Public Health, \\ Boston, MA \\ ${ }^{2}$ MGH Global Health, Massachusetts General Hospital, Boston, MA; Harvard Center for \\ Population and Development Studies, Cambridge, MA
}

\begin{abstract}
HIV-related stigma compromises both HIV prevention and treatment and has recently been described as a barrier to utilization of skilled childbirth services in sub-Saharan Africa. This study uses the 2011 Uganda Demographic Health Survey to estimate the associations between HIVrelated stigma, measured both at the individual and community level, and use of facility delivery among women. Consistent with theoretical predictions, higher levels of stigma are associated with reduced likelihood of facility delivery. The negative relationship between stigma and facility delivery is especially pronounced when stigma is measured at the community level, highlighting the importance of understanding the proximate context of HIV-related stigma and its potential effects on behavior. Reducing the stigma of HIV will be critical to achieving the twin goals of reducing overall maternal mortality and preventing mother-to-child HIV transmission.
\end{abstract}

\section{Keywords}

HIV stigma; skilled childbirth services; maternal health; PMTCT

\section{Introduction}

Despite progress toward Millennium Development Goal (MDG) 5 to achieve a 75\% reduction in the maternal mortality ratio by 2015 , only sixteen countries are thought to have achieved MDG 5 (1), and the world is far from achieving the new Sustainable Development Goal (SDG) 3.1 target of reaching a global maternal mortality ratio of less than 70 per 100,000 live births (2). Nearly 300,000 maternal deaths related to pregnancy occurred in 2013 (1), and the countries with the highest mortality rates are all located in sub-Saharan Africa (3-6). A primary driver of these maternal deaths, particularly in rural areas $(6,7)$, is lack of access to appropriate maternal health care, notably skilled birth attendance and utilization of health facilities for childbirth (8-12). A number of sociodemographic, sociocultural, and structural correlates of facility delivery have been identified, including educational attainment $(13,14)$, economic status $(15-18)$, geographic proximity $(5,19,20)$,

*Correspondence: Courtney K Ng, Harvard T.H. Chan School of Public Health, 665 Huntington Ave, 11th floor, Boston, MA 02115 (cng@mail.harvard.edu). 
out of pocket costs $(17,21,22)$, autonomy and empowerment $(23,24)$, and perceived benefit or need (25-27). Literature reviews trying to understand the determinants of facility delivery use have also been conducted $(28,29)$.

A growing body of literature has identified HIV-related stigma as structural factor that exerts influence on women's decisions to avoid facilities for childbirth (30-34). Despite ongoing HIV treatment scale-up, qualitative data from Kenya show that women of unknown serostatus avoid facility delivery because they fear being tested for HIV and having their test results involuntarily disclosed $(30,34)$. For women who are HIV-positive, participating in prevention of mother-to-child transmission (PMTCT) programs and having to receive services from a designated health facility may also be stigmatizing $(32,35-37)$. With the exception of the important studies by Turan et al. $(30,31,34,38,39)$, however, there have been no population-based studies examining this important issue. Furthermore, this existing body of literature is limited in its conceptualization of HIV-related stigma as an individuallevel phenomenon. Yet the proximate context of stigma, defined as the intensity of stigma present in a particular context near an individual, is an important community-level attribute that may have an important impact on health behaviors (40-42).

To address this gap in the literature, we used data from the 2011 Uganda Demographic and Health Survey to examine the relationship between HIV-related stigma and utilization of skilled childbirth services. Uganda represents an important setting in which to examine this study question because its total fertility rate is one of the highest in the world, the maternal mortality ratio is 360 deaths per 100,000 live births, and only $57 \%$ of pregnant women give birth in health facilities (3). In Uganda, the HIV epidemic is generalized (43), the implementation of PMTCT is widespread $(3,44)$, and HIV is highly stigmatized $(45,46)$. Furthermore, Uganda recently implemented the "B+ option" through the HIV and AIDS Prevention and Control Act (47), mandating HIV testing for all pregnant women and their partners and allowing providers to disclose women's HIV status (48), potentially exposing HIV-positive women to discrimination and abuse (49). We hypothesized that higher levels of HIV-related stigma, measured either at the individual or community level, would be associated with reduced likelihood of health facility delivery.

\section{Methods}

\section{Data source and variables}

Our analysis is based on the 2011 Uganda Demographic Health Survey (DHS), which is a publicly available, population-based survey implemented by the Uganda Bureau of Statistics with technical assistance from ICF International (through the MEASURE DHS project), the Ugandan Ministry of Health, Makerere University School of Public Health, and the Biochemistry Department of Makerere University. The DHS employed a multistage stratified design with probabilistic sampling, with enumeration areas selected from a list of previously sampled clusters and a fixed number of households selected from within each cluster. All women of reproductive age (15-49 years) who were either permanent household residents or visitors who slept there the night before the survey were eligible for participation. Among the 10,086 households selected, the response rate was 94 percent. Additional details regarding pretesting, field training, and survey implementation can be 
found in the DHS country report (50). For this specific analysis, we only included women who had heard of HIV and who had given birth in the five years prior to the survey. The reason for the first sample restriction is because the questions about HIV-related stigma (described in more detail below) were administered only to women who indicated that they had heard of HIV. The reason for the second sample restriction is because questions about place of delivery were only asked of women who had given birth within the previous 5 years.

The main outcome variable was whether or not the study participant had utilized a health facility for her most recent childbirth. We selected this measure given that it is a commonly used health systems indicator relevant to maternal mortality (51-54). All public and private hospitals, health centers, and clinics were counted as health facilities in our analysis. We limited the analysis to the most recent childbirth (rather than analyzing all births in the five years prior to the survey) because it was the observation most proximal to measurement of the exposure. Depending on the woman's age, in some cases the "most recent" childbirth could have been up to five years prior to the survey (thereby posing a potential problem for interpretation of the analysis with an outcome that could in some cases precede the exposure by many years). To address this possibility, we conducted a sensitivity analysis limiting the sample to women whose most recent childbirth occurred in 2010 and 2011 (i.e., so that the exposure would be as contemporaneous with the outcome as possible).

The main explanatory variable of interest was HIV-related stigma, reflected in desires for social distance $(55,56)$ (e.g., due to instrumental concerns about casual transmission (57) and other factors attached to the negative social meaning of HIV/AIDS), captured through three DHS questions: "Would you buy fresh vegetables from a shopkeeper or vendor if you knew that this person had the AIDS virus?" "If a member of your family became sick with AIDS, would you be willing to care for her or him in your own household?" and "In your opinion, if a female teacher has the AIDS virus but is not sick, should she be allowed to continue teaching in the school?" Although the DHS included another HIV-related stigma question about anticipated stigma ("If a member of your family got infected with the AIDS virus, would you want it to remain a secret or not?") $(55,58)$, we only included the social distance measures in our analyses due to limitations on the interpretability of the DHS question on anticipated stigma as described by Nyblade et al. (59) and Yoder \& Nyblade (60), and given its removal from the latest round of the DHS. The three social distance questions were summed into a single index and analyzed as a continuous variable (ranging from 0-3) for the main analysis, but we also conducted sensitivity analyses using the three social distance measures separately.

To measure HIV-related stigma at the community level, we created summary variables representing the mean level of each stigma variable at the level of the primary sampling unit (PSU) (excluding the index participant from the calculation). The PSU was the smallest clustering unit of analysis. In the DHS, the PSU typically represents a village or cluster of villages in rural areas and a ward or residential neighborhood in urban areas. For ease of exposition, in this manuscript we use the term "village" or "community" to refer to this level of analysis. Villages with fewer than five female participants were removed from the analysis (61). For each woman in our sample who lived in a village with five or more 
women, a village-level mean stigma score that included all individuals (men and women) in the village except for the participant herself was generated for each stigma measure. In addition to the village-level stigma variables, we examined two other village-level variables, education and literacy, as potential confounders (62). In the multivariable regression models (described in more detail below), estimates were adjusted for age, marital status, residence, education, occupation, economic status, religion, parity of birth, and perceived distance to clinic. Economic status was based on the participant's quintile of household asset wealth index as provided by the DHS, which was calculated by applying principal components analysis to a set of household possessions and housing characteristics of each participant (63). Finally, we included a dichotomous indicator denoting whether the participant reported attending four or more antenatal care visits (64-66).

\section{Statistical Analysis}

All statistical analyses were conducted using Stata software (version 11.2, StataCorp LLP, College Station, Tex.). We fitted multivariable logistic regression models to the data, specifying health facility delivery as the dependent variable and HIV-related stigma, measured by the social distance index and individual social distance items, as well as the other potential confounders, as the explanatory variables. Cronbach's alpha was calculated to assess the internal consistency of the social distance index. First we estimated the association between individual-level stigma and health facility delivery. Then, after adjusting for covariates, we added village-level stigma to assess its additional explanatory power. In addition to the estimated odds ratios, we also computed marginal effects to aid in interpretation (67). All regression models employed cluster-correlated robust estimates of variance to account for dependence of observations within villages (68-70).

To explore potential explanations for any statistically significant associations found between stigma and health facility delivery, we tested for effect modification by prior HIV testing and women's healthcare decision making-power within the household. We examined these two variables specifically because fear of HIV testing has been proposed as a potential reason for why women avoid health facility delivery $(30,34,71)$, and previous studies assumed stigma affects maternal health care utilization by shaping women's attitudes and choices towards health facility delivery $(30,31)$. We hypothesized that the negative association between stigma and health facility delivery would be stronger among women who had never been tested for HIV and among women who had relative autonomy in health care decisionmaking within the household. To assess the robustness of our findings, we conducted several sensitivity analyses. First, because the internal consistency of the social distance index was relatively low, we fitted three multivariable regression models using each of the three individual social distance items as the main explanatory variable. Second, as described above, to ensure that the exposure and outcome were as contemporaneous as possible given the limitations of the data, we restricted our sample to women who gave birth within the two-year window of the survey date (2010-11). Third, we fitted the same multivariable regression models specifying skilled birth attendance as the dependent variable. 


\section{Results}

Our sample consisted of 4898 women ages 15 to 49 who had heard of HIV and who had given birth between 2007 and 2011. Summary characteristics of the sample are displayed in Table 1. The Cronbach's alpha for the social distance index was 0.58. In our sample, 2064 (42\%) women endorsed at least one of the items in the social distance index. Most (3025 [62\%]) women utilized a health facility for their most recent childbirth. 1107 (37\%) women who had utilized a health facility endorsed at least one of the social distance items, compared to 957 (51\%) women who had not utilized a health facility $(\chi 2=99.7415$, $\mathrm{P}<0.001)$. Multivariable regression suggested a negative and statistically significant association between facility delivery and social distance (AOR=0.86; 95\% CI, 0.80-0.94) (Table 2). Expressed in terms of average marginal effects, each additional point on the social distance index was associated with a 2.7 percentage point lower probability of giving birth in a health facility (Table S1). In terms of the other covariates examined, higher levels of schooling, higher wealth index, first pregnancy, and having attended more than four ANC visits increased the likelihood of facility delivery, while rural residence and citing distance as a barrier decreased the likelihood of facility delivery.

When village-level stigma variables were added to the multivariate regression models, the signs of all estimated coefficients remained the same as in the models with only individuallevel HIV stigma variables (Table 2). However, the addition of village-level stigma variables greatly reduced the strength of the association between individual-level HIV stigma and facility delivery. Women who lived in villages characterized by high levels of social distancing were much less likely to give birth in a health facility ( $\mathrm{AOR}=0.55 ; 95 \% \mathrm{CI}$, $0.40-0.74)$. Stated differently, the predicted probability of facility delivery was 0.71 for women who lived in villages where social distancing was at the 25th percentile of intensity and 0.66 for women who lived in villages where social distancing was at the 75th percentile of intensity. When we included village-level education and literacy in the regression models, the estimated associations between village-level social distance and facility delivery remained statistically significant.

In testing for effect modification by prior HIV testing and women's healthcare decision making-power within the household, neither variable had a statistically significant interaction with stigma (Table 3 ). When we tested the explanatory power of the three social distance items individually, all three items had statistically significant associations with delivery at a health facility. For each item, the inverse association between village-level social distance (e.g., the proportion of persons in the village who would not purchase vegetables from an HIV-positive vendor) and facility delivery was statistically significant and was stronger than the association between the individual-level social distance item and facility delivery (Table S1). The inverse association between willingness to care for a HIVpositive relative and facility delivery was the strongest among the three social distance items ( $\mathrm{AOR}=0.15 ; 95 \% \mathrm{CI}, 0.06-0.37$ ). When we restricted estimation to the women who gave birth within the two-year window of the survey date, the regression results were qualitatively similar to the primary analysis, with a statistically significant inverse association between village-level social distancing and facility delivery $(\mathrm{AOR}=0.51 ; 95 \% \mathrm{CI}, 0.35-0.72)$. Finally, 
village-level social distancing had a similar association with skilled birth attendance as with facility delivery (Table S2).

\section{Discussion}

In this population-based study of 4898 women in Uganda, we found that HIV-related stigma, as measured by social distancing, was negatively associated with utilization of skilled childbirth services. The estimated associations were statistically significant, large in magnitude, and robust to potential confounders. Furthermore, the contextual influence of HIV stigma (i.e., measured at the village level) appeared to be stronger than stigma measured at the individual level. We explored some potential reasons for the observed associations but did not identify any statistically significant effect modifiers suggestive of a mechanism. Taken together, our findings have important implications for policy and programmatic work in the field.

Our study confirms the findings of other studies showing that HIV-related stigma has a negative impact on maternal healthcare utilization (30-32, 34). A statistically significant negative association was observed between social distance and facility delivery, which was large in magnitude and robust to several different sensitivity analyses. When we examined specific expressions of social distance separately, willingness to care for a HIV positive relative was the most predictive of facility delivery. Although making comparisons to previous studies can be difficult given different study designs and varied reporting, the magnitude of our estimates using the social distance index can be compared to other, more well-established, risk factors in the literature. For example, the difference in predicted probability of facility delivery for a woman living in a village characterized by a high level of social distancing compared to a low level of social distancing was comparable to living an additional 5-10 km away from a health facility with a midwife or doctor on call for 24 hours (19). Thus, the estimated associations can be considered relatively large in magnitude.

There are several plausible explanations for the observed association between social distancing from HIV-related stigma and health facility delivery, such as the fear of being tested for HIV $(30,34,71)$ or the fear of involuntary disclosure to others $(31,34)$. In Uganda, where PMTCT messaging is strong and HIV-positive women are encouraged to give birth in health facilities, women of unknown serostatus may fear being identified as HIV-positive (irrespective of whether they actually have a positive test result) if they were to do the same (32). Consistent with this hypothesis, a recent study from Kenya showed that lack of serostatus disclosure was negatively associated with facility delivery (39). The impacts of stigma may hold irrespective of women's actual serostatus: HIV-positive women may avoid delivering at health facilities for fear of involuntary disclosure (72), while women of unknown serostatus may avoid delivering at health facilities for fear of being associated with HIV.

Notably, social distancing measured at the level of the village had an even stronger negative association with facility delivery. Our estimates suggest that women living in villages where HIV is highly stigmatized -- irrespective of their personal attitudes toward persons with HIV -- were more likely to avoid giving birth in health facilities. This novel finding is consistent 
with themes that emerged in a qualitative study from Malawi, in which HIV-related stigma in the community was cited as a barrier to PMTCT uptake (72). It is also consistent with the finding of Turan et al. that perceived community discrimination against people with HIV was associated with greater odds of anticipating HIV stigma, which may then reduce maternal health care utilization (38). The stronger association with stigma at the village vs. individual level highlights the importance of understanding stigma as a structural variable rather than simply as a matter of individual belief (42), especially given that health behaviors like utilization of skilled childbirth services may be heavily shaped by structural factors and social norms (73).

While our findings are consistent with the potential explanations detailed above, we found no evidence for effect modification by prior HIV testing history or by health care decisionmaking power. It is therefore possible that women avoided facility delivery not out of fear of HIV testing but due to fear of involuntary HIV disclosure (in the event of a positive HIV test) or of being labeled as having HIV. However, the lack of effect modification by health care decision-making power also suggests that women were not necessarily making deliberate decisions about their delivery choices based on stigma. Further research is needed to understand the mechanisms through which HIV-related stigma compromises women's reproductive health.

Interpretation of our findings is subject to several limitations. First, we did not have access to participants' known HIV serostatus, so we could not assess the extent to which the associations between stigma and facility delivery differed for HIV-positive vs. HIV-negative women. The Uganda AIDS Indicator Survey (AIS) was implemented in Uganda in 2011, but the AIS could not be used for our analysis because (a) even though AIS participants are tested for HIV, the test results are not communicated to participants prior to the survey so it cannot be definitively shown that the HIV-positive participants are aware that they are HIVpositive (74); and (b) the AIS contains data on HIV-related stigma but does not contain data on women's birth histories. A second limitation is that the DHS questions on HIV-related stigma did not allow us to examine other aspects of HIV stigma, including enacted stigma (58) or internalized stigma (55) (among HIV-positive women), which may affect women's delivery choices differently. The many shortcomings of the only anticipated stigma question in the DHS also prevented us from using it for our analyses, restricting our analyses to the three social distance DHS questions $(59,60)$. Third, these data are cross-sectional, thereby precluding our ability to draw inferences about the extent to which the observed associations are causal. It is possible, for example, that women's childbirth experiences could have shaped their individual attitudes about persons with HIV -- thereby contaminating our estimated associations between facility delivery and individual-level stigma. However, it is unlikely that that an individual women's childbirth experiences could have shaped attitudes about persons with HIV in her village, so we believe our findings about community-level stigma are unlikely to have been affected by this potential source of bias. In a resourcelimited setting with a generalized HIV epidemic and one of the highest total fertility rates in the world, we demonstrate that reducing HIV-related stigma may have important spillover impacts on maternal and child health. Our findings suggest that interventions should target individuals to reduce stigmatizing attitudes, but they should also aim to reduce stigma at the level of the community through the use of structural interventions $(75,76)$ to encourage an 
environment that does not isolate or discriminate against persons with HIV. Specifically, in Uganda where the 2014 HIV and AIDS Prevention and Control Act mandates HIV testing for pregnant women and their partners and permits health care providers to disclose HIV serostatus, increased efforts to reduce HIV-related stigma will be needed to encourage pregnant women not to avoid health facilities for childbirth. Policy-makers should also be aware of potential inadvertent consequences of PMTCT campaigns, such as associating facility delivery and maternal healthcare utilization with HIV infection. As PMTCT efforts are promoted more widely, parallel efforts to reduce HIV-related stigma should be scaled up as well. Tackling HIV-related stigma will help advance the twin goals of lowering maternal and child mortality and HIV prevalence (76-78).

\section{Conclusion}

In summary, our study provides new quantitative evidence about the negative association between HIV-related stigma and women's decisions to utilize skilled childbirth services. Our findings reinforce the urgency to reduce HIV-related stigma, particularly at a structural level, in settings where HIV is prevalent and skilled childbirth services may inadvertently take on social meaning. The benefits of a non-stigmatizing environment on the use of skilled childbirth services and maternal mortality are essential for both HIV-positive and HIVnegative women.

\section{Supplementary Material}

Refer to Web version on PubMed Central for supplementary material.

\section{Acknowledgement:}

We would like to thank Measure DHS for access and authorization to the 2011 Uganda Demographic Health Survey data files for research purposes. The authors received no specific funding for this study and acknowledge salary support from U.S. National Institutes of Health K23MH096620. The funders had no role in study design, data collection and analysis, decision to publish, or preparation of the manuscript.

\section{References}

1. Kassebaum NJ, Bertozzi-Villa A, Coggeshall MS, Shackelford KA, Steiner C, Heuton KR, et al. Global, regional, and national levels and causes of maternal mortality during 1990-2013: a systematic analysis for the Global Burden of Disease Study 2013. The Lancet. 2014.

2. United Nations. Goal 3 Ensure healthy lives and promote well-being for all at all ages. 2015; Available at: https://sustainabledevelopment.un.org/sdg3. Accessed Dec 27, 2015.

3. Requejo J, Bryce J, Victora C. Fulfilling the health agenda for women and children: the 2014 report. Conference draft.

4. Hill K, Thomas K, AbouZahr C, Walker N, Say L, Inoue M, et al. Estimates of maternal mortality worldwide between 1990 and 2005: an assessment of available data. The Lancet. 2007;370(9595): 1311-9.

5. Mpembeni RN, Killewo JZ, Leshabari MT, Massawe SN, Jahn A, Mushi D, et al. Use pattern of maternal health services and determinants of skilled care during delivery in Southern Tanzania: implications for achievement of MDG-5 targets. BMC pregnancy and childbirth. 2007;7(1):29. [PubMed: 18053268]

6. Ronsmans C, Graham WJ, group LMSSs. Maternal mortality: who, when, where, and why. The Lancet. 2006;368(9542):1189-200. 
7. Kerber KJ, de Graft-Johnson JE, Bhutta ZA, Okong P, Starrs A, Lawn JE. Continuum of care for maternal, newborn, and child health: from slogan to service delivery. The Lancet. 2007;370(9595): 1358-69.

8. Campbell OM, Graham WJ, group LMSSs. Strategies for reducing maternal mortality: getting on with what works. The Lancet. 2006;368(9543):1284-99.

9. Koblinsky MA, Campbell O, Heichelheim J. Organizing delivery care: what works for safe motherhood? Bulletin of the World Health Organization. 1999;77(5):399. [PubMed: 10361757]

10. de Bernis L, Sherratt DR, AbouZahr C, Van Lerberghe W. Skilled attendants for pregnancy, childbirth and postnatal care. British medical bulletin. 2003;67(1):39-57. [PubMed: 14711753]

11. Organization WH. Global action for skilled attendants for pregnant women: making pregnancy safer. 2002.

12. WHO U, UNICEF, The World Bank. Reduction of maternal mortality: A joint WHO/UNFPA/ UNICEF/World Bank statement. Geneva: World Health Organization; 199944 p.

13. Raghupathy S. Education and the use of maternal health care in Thailand. Social Science \& Medicine. 1996;43(4):459-71. [PubMed: 8844947]

14. Ikeako L, Onah H, Iloabachie G. Influence of formal maternal education on the use of maternity services in Enugu, Nigeria. Journal of Obstetrics \& Gynecology. 2006;26(1):30-4.

15. Ahmed S, Creanga AA, Gillespie DG, Tsui AO. Economic status, education and empowerment: implications for maternal health service utilization in developing countries. PLoS One. 2010;5(6):e11190. [PubMed: 20585646]

16. Anyait A, Mukanga D, Oundo GB, Nuwaha F. Predictors for health facility delivery in Busia district of Uganda: a cross sectional study. BMC pregnancy and childbirth. 2012;12(1):132. [PubMed: 23167791]

17. Mayhew M, Hansen PM, Peters DH, Edward A, Singh LP, Dwivedi V, et al. Determinants of skilled birth attendant utilization in Afghanistan: a cross-sectional study. American journal of public health. 2008;98(10):1849. [PubMed: 18703445]

18. Say L, Raine R. A systematic review of inequalities in the use of maternal health care in developing countries: examining the scale of the problem and the importance of context. Bulletin of the World Health Organization. 2007;85(10):812-9. [PubMed: 18038064]

19. Gabrysch S, Cousens S, Cox J, Campbell OM. The influence of distance and level of care on delivery place in rural Zambia: a study of linked national data in a geographic information system. PLoS medicine. 2011;8(1):150.

20. Lohela TJ, Campbell OM, Gabrysch S. Distance to care, facility delivery and early neonatal mortality in Malawi and Zambia. PLoS One. 2012;7(12):e52110. [PubMed: 23300599]

21. Kruk ME, Mbaruku G, Rockers PC, Galea S. User fee exemptions are not enough: out of pocket payments for 'free' delivery services in rural Tanzania. Tropical medicine \& international health. 2008;13(12):1442-51. [PubMed: 18983268]

22. Smith KV, Sulzbach S. Community-based health insurance and access to maternal health services: evidence from three West African countries. Social Science \& Medicine. 2008;66(12):2460-73. [PubMed: 18362047]

23. Adjiwanou V, LeGrand T. Gender inequality and the use of maternal healthcare services in rural sub-Saharan Africa. Health \& place. 2014;29:67-78. [PubMed: 24994096]

24. Mrisho M, Schellenberg JA, Mushi AK, Obrist B, Mshinda H, Tanner M, et al. Factors affecting home delivery in rural Tanzania. Tropical medicine \& international health. 2007;12(7):862-72. [PubMed: 17596254]

25. Amooti-Kaguna B, Nuwaha F. Factors influencing choice of delivery sites in Rakai district of Uganda. Social Science \& Medicine. 2000;50(2):203-13. [PubMed: 10619690]

26. Kyomuhendo GB. Low use of rural maternity services in Uganda: impact of women's status, traditional beliefs and limited resources. Reproductive health matters. 2003;11(21):16-26. [PubMed: 12800700]

27. Griffiths P, Stephenson R. Understanding Users' Perspectives of Barriers to Maternal Health Care Use in Maharashtra, India. Journal of biosocial science. 2001;33(03):339-59. [PubMed: 11446398] 
28. Gabrysch S, Campbell OM. Still too far to walk: literature review of the determinants of delivery service use. BMC pregnancy and childbirth. 2009;9(1):34. [PubMed: 19671156]

29. Thaddeus S, Maine D. Too far to walk: maternal mortality in context. Social Science \& Medicine. 1994;38(8):1091-110. [PubMed: 8042057]

30. Turan JM, Hatcher AH, Medema-Wijnveen J, Onono M, Miller S, Bukusi EA, et al. The role of HIV-related stigma in utilization of skilled childbirth services in rural Kenya: a prospective mixedmethods study. PLoS Medicine. 2012;9(8):e1001295 Epub 2012 Aug 21. [PubMed: 22927800]

31. Medema-Wijnveen JS, Onono M, Bukusi EA, Miller S, Cohen CR, Turan JM. How perceptions of HIV-related stigma affect decision-making regarding childbirth in rural Kenya. PLoS One. 2012;7(12).

32. Turan JM, Nyblade L. HIV-related stigma as a barrier to achievement of global PMTCT and maternal health goals: a review of the evidence. AIDS and Behavior. 2013;17(7):2528-39. [PubMed: 23474643]

33. International A. Struggle for Maternal Health: Barriers to Antenatal Care in South Africa. Report. London: Amnesty International, 2014109 2014. Report No.

34. Turan JM, Miller S, Bukusi E, Sande J, Cohen C. HIV/AIDS and maternity care in Kenya: how fears of stigma and discrimination affect uptake and provision of labor and delivery services. AIDS care. 2008;20(8):938-45. [PubMed: 18777222]

35. Suthar AB, Hoos D, Beqiri A, Lorenz-Dehne K, McClure C, Duncombe C. Integrating antiretroviral therapy into antenatal care and maternal and child health settings: a systematic review and meta-analysis. Bulletin of the World Health Organization. 2013;91(1):46-56. [PubMed: 23397350]

36. Both J, Van Roosmalen J. The impact of Prevention of Mother to Child Transmission (PMTCT) programmes on maternal health care in resource.poor settings: looking beyond the PMTCT programme--a systematic review. BJOG: An International Journal of Obstetrics \& Gynaecology. 2010;117(12):1444-50. [PubMed: 20937071]

37. Thorsen VC, Sundby J, Martinson F. Potential Initiators of HIV-related Stigmatization: Ethical and Programmatic Challenges for PMTCT Programs Developing World Bioethics. 2008;8(1):43-50. [PubMed: 18302543]

38. Cuca YP, Onono M, Bukusi E, Turan JM. Factors associated with pregnant women's anticipations and experiences of HIV-related stigma in rural Kenya. AIDS care. 2012;24(9):1173-80. [PubMed: 22799618]

39. Spangler SA, Onono M, Bukusi EA, Cohen CR, Turan JM. HIV-positive status disclosure and use of essential PMTCT and maternal health services in rural Kenya. Journal of acquired immune deficiency syndromes (1999). 2014;67(Suppl 4):S235. [PubMed: 25436823]

40. Tsai AC, Subramanian S. Proximate context of gender-unequal norms and women's HIV risk in sub-Saharan Africa. AIDS. 2012;26(3):381-6. [PubMed: 22045344]

41. Hung KJ, Scott J, Ricciotti HA, Johnson TR, Tsai AC. Community-level and individual-level influences of intimate partner violence on birth spacing in sub-Saharan Africa. Obstetrics \& Gynecology. 2012;119(5):975-82. [PubMed: 22525908]

42. Kelly JD, Weiser SD, Tsai AC. Proximate Context of HIV Stigma and Its Association with HIV Testing in Sierra Leone: A Population-Based Study. AIDS and Behavior. 2015:1-6. [PubMed: 24668254]

43. Uganda AIs. Demographic and Health Surveys, ICF International 2012.

44. Bannink-Mbazzi F, Lowicki-Zucca M, Ojom L, Kabasomi SV, Esiru G, Homsy J. High PMTCT program uptake and coverage of mothers, their partners, and babies in northern Uganda: achievements and lessons learned over 10 years of implementation (2002-2011). JAIDS Journal of Acquired Immune Deficiency Syndromes. 2013;62(5):e138-e45. [PubMed: 23274930]

45. Chan BT, Weiser SD, Boum Y, Siedner MJ, Mocello AR, Haberer JE, et al. Persistent HIV-related stigma in rural Uganda during a period of increasing HIV incidence despite treatment expansion. AIDS. 2015;29(1):83-90. [PubMed: 25268886]

46. Tsai AC, Venkataramani AS. The causal effect of education on HIV stigma in Uganda: Evidence from a natural experiment. Social Science \& Medicine. 2015;142:37-46. [PubMed: 26282707]

47. HIV and AIDS Prevention and Control Act, (2014). 
48. Uganda: Deeply Flawed HIV Bill Approved. Human Rights Watch; 2014; Available at: https:// www.hrw.org/news/2014/05/13/uganda-deeply-flawed-hiv-bill-approved. Accessed July 17, 2015.

49. McGill MAG-MC, Rates SMS. barriers and outcomes of HIV serostatus disclosure among women in developing countries: Implications for prevention of mother-to-child transmission programmes. Bull World Health Organ. 2004;82:299-307. [PubMed: 15259260]

50. Uganda Bureau of Statistics II. Uganda Demographic and Health Survey. The DHS Program, 2012.

51. Montagu D, Yamey G, Visconti A, Harding A, Yoong J. Where do poor women in developing countries give birth? A multi-country analysis of demographic and health survey data. PLoS One. 2011;6(2):e17155. [PubMed: 21386886]

52. Joharifard S, Rulisa S, Niyonkuru F, Weinhold A, Sayinzoga F, Wilkinson J, et al. Prevalence and predictors of giving birth in health facilities in Bugesera District, Rwanda. BMC public health. 2012;12(1):1049. [PubMed: 23217157]

53. Kitui J, Lewis S, Davey G. Factors influencing place of delivery for women in Kenya: an analysis of the Kenya demographic and health survey, 2008/2009. BMC pregnancy and childbirth. 2013;13(1):40. [PubMed: 23414104]

54. Wang W, Alva S, Wang S, Fort A. Levels and trends in the use of maternal health services in developing countries. 2011.

55. Link BG, Cullen FT, Frank J, Wozniak JF. The social rejection of former mental patients: Understanding why labels matter. American journal of Sociology. 1987:1461-500.

56. Bogardus ES. Measuring social distance. Journal of applied sociology. 1925;9(2):299-308.

57. Pryor JB, Reeder GD, Vinacco R, Kott TL. The Instrumental and Symbolic Functions of Attitudes toward Persons with AIDS1. Journal of Applied Social Psychology. 1989;19(5):377-404.

58. Scambler G, Hopkins A. Being epileptic: coming to terms with stigma. Sociology of Health \& Illness. 1986;8(1):26-43.

59. Tanzania Stigma Indicator Working Group. Measuring HIV stigma: Results of a field-test in Tanzania. Washington DC: Synergy 2005.

60. Yoder PS, Nyblade L. Comprehension of Questions in the Tanzania AIDS: Indicator Survey: ORC Macro, MEASURE DHS; 2004.

61. Adjiwanou V, LeGrand T. Does antenatal care matter in the use of skilled birth attendance in rural Africa: a multi-country analysis. Social Science \& Medicine. 2013;86:26-34. [PubMed: 23608091]

62. Ackerson LK, Kawachi I, Barbeau EM, Subramanian S. Effects of individual and proximate educational context on intimate partner violence: a population-based study of women in India. American journal of public health. 2008;98(3):507. [PubMed: 18235066]

63. Filmer D, Pritchett LH. Estimating wealth effects without expenditure Data--Or tears: An application to educational enrollments in states of India. Demography. 2001;38(1):115-32. [PubMed: 11227840]

64. Ensor T, Cooper S. Overcoming barriers to health service access: influencing the demand side. Health policy and planning. 2004;19(2):69-79. [PubMed: 14982885]

65. Mishra V, Retherford RD. The effect of antenatal care on professional assistance at delivery in rural India. Population Research and Policy Review. 2008;27(3):307-20.

66. Bloom SS, Lippeveld T, Wypij D. Does antenatal care make a difference to safe delivery? A study in urban Uttar Pradesh, India. Health policy and planning. 1999;14(1):38-48. [PubMed: 10351468]

67. Bartus T Estimation of marginal effects using margeff. Stata journal. 2005;5(3):309-29.

68. Froot KA. Consistent covariance matrix estimation with cross-sectional dependence and heteroskedasticity in financial data. Journal of Financial and Quantitative Analysis. 1989;24(03): 333-55.

69. Rogers W Regression standard errors in clustered samples. Stata technical bulletin. 1994;3(13).

70. Williams RL. A note on robust variance estimation for cluster-correlated data. Biometrics. 2000;56(2):645-6. [PubMed: 10877330] 
71. Turan JM, Bukusi EA, Onono M, Holzemer WL, Miller S, Cohen CR. HIV/AIDS stigma and refusal of HIV testing among pregnant women in rural Kenya: results from the MAMAS Study. AIDS and Behavior. 2011;15(6):1111-20. [PubMed: 20827573]

72. Iroezi ND, Mindy D, Kawale P, Chikowi G, Jansen PA, Hoffman RM. A qualitative analysis of the barriers and facilitators to receiving care in a prevention of mother-to-child program in Nkoma, Malawi. African Journal of Reproductive Health. 2013;17(4):11.

73. Parkhurst JO, Rahman SA, Ssengooba F. Overcoming access barriers for facility-based delivery in low-income settings: insights from Bangladesh and Uganda. Journal of health, population, and nutrition. 2006;24(4):438.

74. Tsai AC. Socioeconomic Gradients in Internalized Stigma Among 4,314 Persons with HIV in SubSaharan Africa. AIDS and Behavior. 2015;19(2):270-82. [PubMed: 25572833]

75. Tsai AC. A typology of structural approaches to HIV prevention: a commentary on Roberts and Matthews. Social Science \& Medicine. 2012;75(9):1562-7. [PubMed: 22877933]

76. Nayar US, Stangl AL, De Zalduondo B, Brady LM. Reducing stigma and discrimination to improve child health and survival in low-and middle-income countries: Promising approaches and implications for future research. Journal of health communication. 2014;19(sup1):142-63. [PubMed: 25207451]

77. Gorman SE. A new approach to maternal mortality: the role of HIV in pregnancy. International Journal of Women's Health. 2013;5:271.

78. Turan JM, Nyblade L. Global Maternal and Child Health Goals Will Not be Achieved Without Addressing HIV-Related Stigma. JAIDS Journal of Acquired Immune Deficiency Syndromes. 2013;64(1):e9-e10. [PubMed: 23941856] 
Table 1.

Summary characteristics of the sample of women ages 15 to 49

\begin{tabular}{|c|c|}
\hline & N $(\%)$ or Mean (SD) \\
\hline \multicolumn{2}{|l|}{ Dependent variable } \\
\hline Delivery at a health facility ${ }^{a}$ & $3025(62)$ \\
\hline \multicolumn{2}{|l|}{ Independent variables } \\
\hline Accepting attitudes for all HIV stigma questions & $1272(26)$ \\
\hline Social distance index ${ }^{b}$ & $0.66(0.90)$ \\
\hline Female teacher infected with HIV should not be allowed to teach & $1236(25)$ \\
\hline Not willing to care for relative with HIV & $541(11)$ \\
\hline Would not buy vegetables from vendor with HIV & $1448(30)$ \\
\hline \multicolumn{2}{|l|}{ Explanatory variables } \\
\hline Age (years) & $28.69(7.12)$ \\
\hline Married or living with partner & $4123(84)$ \\
\hline \multicolumn{2}{|l|}{ Education } \\
\hline No formal schooling & $855(17)$ \\
\hline Primary school & $2844(58)$ \\
\hline Secondary school & $966(20)$ \\
\hline Higher education & $233(5)$ \\
\hline \multicolumn{2}{|l|}{ Residence } \\
\hline Urban & $1184(24)$ \\
\hline Rural & $3714(76)$ \\
\hline \multicolumn{2}{|l|}{ Wealth index ${ }^{c}$} \\
\hline Poorest & $1190(24)$ \\
\hline Poorer & $929(19)$ \\
\hline Middle & $839(17)$ \\
\hline Less poor & $793(16)$ \\
\hline Least poor & $1147(23)$ \\
\hline \multicolumn{2}{|l|}{ Religion } \\
\hline Catholic & $2132(44)$ \\
\hline Protestant & $1377(28)$ \\
\hline Muslim & $685(14)$ \\
\hline Pentecostal & $565(12)$ \\
\hline Seventh Day Adventist & $87(2)$ \\
\hline Other & $52(1)$ \\
\hline First pregnancy & $808(16)$ \\
\hline Four or more antenatal visits & $2554(52)$ \\
\hline Distance a big barrier to health care facility ${ }^{d}$ & $2126(43)$ \\
\hline Total number of women & 4898 \\
\hline
\end{tabular}

$S D$ Standard deviation 
${ }^{a}$ Facility delivery includes delivery at all types of health facilities as indicated in the DHS survey.

$b$

The social distance index was generated by summing the total number of responses to three questions about preferences for social distance from persons with HIV, with responses indicating a negative view of persons with HIV coded to equal 1. The three questions were, "Would you buy fresh vegetables from a shopkeeper or vendor if you knew that this person had the AIDS virus?" "If a member of your family became sick with AIDS, would you be willing to care for her or him in your own household?" "In your opinion, if a female teacher has the AIDS virus but is not sick, should she be allowed to continue teaching in the school?" The scale ranges from 1 to 3 , with higher values indicating a greater degree of stigma.

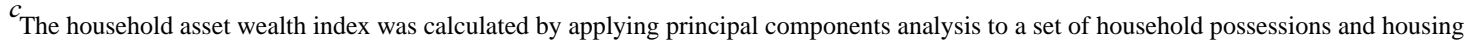
characteristics. The index is then defined as the first principal component and used to categorize participants into quintiles of household assest wealth. Further details on the construction of the asset index can be found in Filmer and Pritchett (62).

$d$ Distance as a barrier to health facility delivery was a dichotomous variable based on a question about the participant's perceived barriers to getting medical advice or treatment. Responses indicating distance to the health facility is a "big problem" are coded to equal 1. 
Table 2.

Social distance as correlates of health facility delivery

\begin{tabular}{|c|c|c|c|c|}
\hline \multirow[t]{2}{*}{ Variables } & \multicolumn{2}{|c|}{ individual-level social distance $^{a}$ only } & \multicolumn{2}{|c|}{$\begin{array}{l}\text { individual- and community-level social } \\
\text { distance }\end{array}$} \\
\hline & AOR & {$[95 \% \mathrm{CI}]$} & AOR & {$[95 \% \mathrm{CI}]$} \\
\hline \multicolumn{5}{|l|}{ HIV-related stigma } \\
\hline Individual-level stigma & $0.863^{* * *}$ & {$[0.80,0.94]$} & $0.915^{*}$ & {$[0.85,0.99]$} \\
\hline Village-level stigma ${ }^{b}$ & & & $0.546^{* * *}$ & {$[0.40,0.74]$} \\
\hline Age (years) & 0.999 & {$[0.99,1.01]$} & 0.998 & {$[0.99,1.01]$} \\
\hline \multicolumn{5}{|l|}{ Marital status } \\
\hline $\begin{array}{l}\text { Never married, widowed, divorced, or } \\
\text { separated }\end{array}$ & Ref & & Ref & \\
\hline Married or living with partner & 0.949 & {$[0.79,1.15]$} & 0.969 & {$[0.80,1.17]$} \\
\hline \multicolumn{5}{|l|}{ Education } \\
\hline No formal schooling & Ref & & Ref & \\
\hline Primary school & $1.325^{* *}$ & {$[1.10,1.60]$} & $1.274 *$ & {$[1.05,1.54]$} \\
\hline Secondary school & $2.168^{* * *}$ & {$[1.63,2.88]$} & $2.045^{* * * *}$ & {$[1.54,2.72]$} \\
\hline Higher education & $6.694^{* * *}$ & {$[3.35,13.39]$} & $6.372^{* * *}$ & {$[3.20,12.69]$} \\
\hline \multicolumn{5}{|l|}{ Residence } \\
\hline Urban & Ref & & Ref & \\
\hline Rural & $0.338^{* * * *}$ & {$[0.24,0.48]$} & $0.375^{* * * *}$ & {$[0.26,0.54]$} \\
\hline \multicolumn{5}{|l|}{ Region of residence } \\
\hline Kampala & Ref & & Ref & \\
\hline Central 1 & 0.794 & {$[0.46,1.38]$} & 0.815 & {$[0.47,1.42]$} \\
\hline Central 2 & 1.413 & {$[0.81,2.46]$} & 1.544 & {$[0.89,2.69]$} \\
\hline East Central & 1.571 & {$[0.89,2.78]$} & 1.746 & {$[0.98,3.11]$} \\
\hline Eastern & 0.958 & {$[0.53,1.73]$} & 1.020 & {$[0.56,1.85]$} \\
\hline Northern & 1.286 & {$[0.72,2.30]$} & 1.108 & {$[0.62,1.99]$} \\
\hline Karamoja & $0.479 *$ & {$[0.25,0.93]$} & 0.736 & {$[0.38,1.42]$} \\
\hline West Nile & 1.427 & {$[0.80,2.54]$} & 1.531 & {$[0.86,2.73]$} \\
\hline Western & 0.893 & {$[0.49,1.62]$} & 0.915 & {$[0.51,1.65]$} \\
\hline Southwestern & 0.579 & {$[0.32,1.04]$} & 0.602 & {$[0.33,1.08]$} \\
\hline \multicolumn{5}{|l|}{ Wealth index ${ }^{c}$} \\
\hline Poorest & Ref & & Ref & \\
\hline Poorer & $1.393^{* *}$ & {$[1.13,1.72]$} & $1.360^{* *}$ & {$[1.10,1.68]$} \\
\hline Middle & $1.454^{* *}$ & {$[1.15,1.84]$} & $1.418^{* *}$ & {$[1.12,1.79]$} \\
\hline Less poor & $1.552^{* * *}$ & {$[1.21,2.00]$} & $1.491^{* * *}$ & {$[1.16,1.91]$} \\
\hline Least poor & $3.335^{* * *}$ & {$[2.37,4.68]$} & $3.139^{* * * *}$ & {$[2.23,4.42]$} \\
\hline First pregnancy & $1.633^{* * *}$ & {$[1.30,2.05]$} & $1.657^{* * * *}$ & {$[1.32,2.08]$} \\
\hline
\end{tabular}




\begin{tabular}{|c|c|c|c|c|}
\hline \multirow[t]{2}{*}{ Variables } & \multicolumn{2}{|c|}{ individual-level social distance $^{a}$ only } & \multicolumn{2}{|c|}{$\begin{array}{l}\text { individual- and community-level social } \\
\text { distance }\end{array}$} \\
\hline & AOR & {$[95 \% \mathrm{CI}]$} & AOR & {$[95 \% \mathrm{CI}]$} \\
\hline Catholic & Ref & & Ref & \\
\hline Protestant & 1.038 & {$[0.85,1.26]$} & 1.030 & {$[0.85,1.25]$} \\
\hline Muslim & 1.148 & {$[0.88,1.50]$} & 1.149 & {$[0.88,1.50]$} \\
\hline Pentecostal & 1.026 & {$[0.81,1.31]$} & 1.003 & {$[0.79,1.27]$} \\
\hline Seventh Day Adventist & 1.673 & {$[0.95,2.94]$} & 1.682 & {$[0.97,2.93]$} \\
\hline Other & 1.006 & {$[0.51,2.00]$} & 0.996 & {$[0.49,2.02]$} \\
\hline \multicolumn{5}{|l|}{ ANC visits } \\
\hline less than 4 antenatal visits & Ref & & Ref & \\
\hline 4+ antenatal visits & $1.778^{* * *}$ & {$[1.57,2.02]$} & $1.780^{* * *}$ & {$[1.57,2.02]$} \\
\hline \multicolumn{5}{|l|}{ Distance a barrier to health facility } \\
\hline Distance not a problem or not a big problem & Ref & & Ref & \\
\hline Distance a big problem & $0.844 *$ & {$[0.73,0.98]$} & $0.860 *$ & {$[0.74,1.00]$} \\
\hline Number of women & 4898 & & 4897 & \\
\hline
\end{tabular}

$A O R$ adjusted odds ratio, $C I$ confidence interval

$p<0.05$,

$* *$

$p<0.01$,

****

$p<0.001$

${ }^{a}$ The social distance index was generated by summing the total number of responses to three questions about preferences for social distance from persons with HIV, with responses indicating a negative view of persons with HIV coded to equal 1 . The three questions were, "Would you buy fresh vegetables from a shopkeeper or vendor if you knew that this person had the AIDS virus?" "If a member of your family became sick with AIDS, would you be willing to care for her or him in your own household?" "In your opinion, if a female teacher has the AIDS virus but is not sick, should she be allowed to continue teaching in the school?" The scale ranges from 1 to 3 , with higher values indicating a greater degree of stigma.

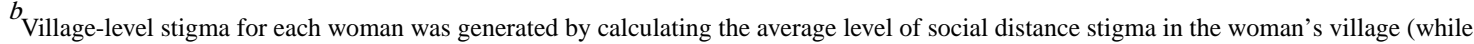
excluding the participant's own stigma score from the calculation).

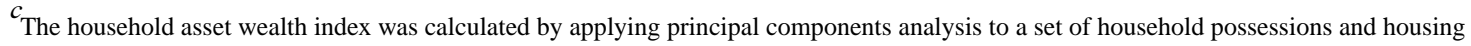
characteristics. The index is then defined as the first principal component and used to categorize participants into quintiles of household assest wealth. Further details on the construction of the asset index can be found in Filmer and Pritchett (62). 
Table 3.

Prior HIV testing and health care decision-making power as potential moderators of the effect of social distance on health facility delivery

\begin{tabular}{|c|c|c|}
\hline \multirow[b]{2}{*}{ - } & \multicolumn{2}{|c|}{ Social distance $^{a}$} \\
\hline & AOR & {$[95 \% \mathrm{CI}]$} \\
\hline \multicolumn{3}{|l|}{ Prior HIV testing } \\
\hline \multicolumn{3}{|l|}{ Association between facility delivery and individual-level stigma } \\
\hline Among women who have had an HIV test $(\mathrm{N}=4286)$ & 0.95 & {$[0.87,1.03]$} \\
\hline Among women who have never had an HIV test $(\mathrm{N}=611)$ & 0.98 & {$[0.80,1.21]$} \\
\hline Interaction term: & \multicolumn{2}{|c|}{$\mathrm{z}=-0.14, \mathrm{P}=0.892$} \\
\hline \multicolumn{3}{|l|}{ Association between facility delivery and community-level stigma } \\
\hline Among women who have had an HIV test $(\mathrm{N}=4286)$ & 0.55 & {$[0.42,0.72]$} \\
\hline Among women who have never had an HIV test $(\mathrm{N}=611)$ & 0.51 & {$[0.29,0.90]$} \\
\hline Interaction term: & \multicolumn{2}{|c|}{$\mathrm{z}=0.02, \mathrm{P}=0.983$} \\
\hline \multicolumn{3}{|c|}{ Health care decision-making power (married or partnered women only) $b$} \\
\hline \multicolumn{3}{|l|}{ Association between facility delivery and individual-level stigma } \\
\hline Among women who do not make their own decisions $(\mathrm{N}=3100)$ & 0.91 & {$[0.82,1.00]$} \\
\hline Among women who make their own decisions ( $\mathrm{N}=958)$ & 0.95 & {$[0.76,1.15]$} \\
\hline Interaction term: & \multicolumn{2}{|c|}{$\mathrm{z}=-0.06, \mathrm{P}=0.952$} \\
\hline \multicolumn{3}{|l|}{ Association between facility delivery and community-level stigma } \\
\hline Among women who do not make their own decisions $(\mathrm{N}=3100)$ & 0.57 & [0.39.0.83] \\
\hline Among women who make their own decisions ( $\mathrm{N}=958)$ & 0.51 & {$[0.31,0.85]$} \\
\hline Interaction term: & \multicolumn{2}{|c|}{$\mathrm{z}=-0.33, \mathrm{P}=0.741$} \\
\hline
\end{tabular}

$A O R$ adjusted odds ratio, $C I$ confidence interval

$*$

$p<0.05$,

*** $p<0.01$,

***

$p<0.001$

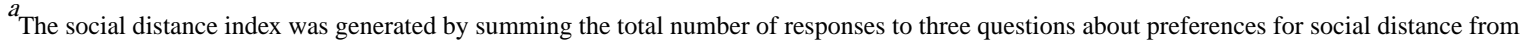
persons with HIV, with responses indicating a negative view of persons with HIV coded to equal 1 . The three questions were, "Would you buy fresh vegetables from a shopkeeper or vendor if you knew that this person had the AIDS virus?" "If a member of your family became sick with AIDS, would you be willing to care for her or him in your own household?" "In your opinion, if a female teacher has the AIDS virus but is not sick, should she be allowed to continue teaching in the school?" The scale ranges from 1 to 3 , with higher values indicating a greater degree of stigma.

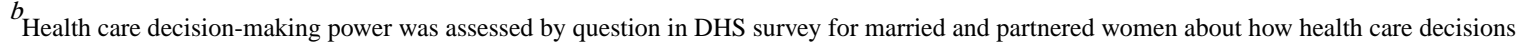
were made in household. A binary variable was generated by coding "1" for women who indicated they make their own health care decisions. 